\title{
The response of grass-cutting ants to natural and synthetic versions of their alarm pheromone
}

\author{
W. O. H. HUGHES*, P.E. HOW SE*, E. F. VILELA $\dagger$ and \\ D. GOUL SON* \\ *Biodiversity and Ecology Division, School of Biological Sciences, University of Southampton, U.K. and $†$ Departemento \\ Biologia Animal, Universidade Federal de Viçosa, Minas Gerais, Brazil
}

\begin{abstract}
The responses of the grass-cutting ants Atta bisphaerica (Forel) and Atta capiguara (Gonçalves) to the main components of their alarm pheromones were examined in simple field bioassays. Both species react most strongly to 4-methyl-3-heptanone, which causes the full range of alarm behaviour and a large increase in the number of individuals near the sources. In later experiments with A. capiguara, this increase was found to be due primarily to attraction, with some arrestment also occurring. The ant response to 4-methyl-3-heptanone was compared with that to crushed heads and to that with whole ants with crushed heads. The pheromone 4-methyl-3-heptanone by itself stimulates the same level of attraction as crushed heads, but results in far less alarm behaviour and arrests fewer ants. Whole ants with crushed heads attract a greater number of ants than the other sources and also cause more alarm behaviour. Bodies alone attract ants, but do not result in alarm behaviour. The main component in both species is the same, supporting the view that alarm pheromones lack species specificity. However, it appears that other components may also be important either as synergists of the main compound, or by stimulating behaviours that would not be observed in its absence.
\end{abstract}

Key words. Alarm, Atta bisphaerica, Atta capiguara, Formicidae, leaf-cutting ants, pheromone.

\section{Introduction}

Alarm behaviour is a common feature of eusocial insect societies and commonly involves the release of an alarm pheromone to communicate alarm to other individuals. Although it is often one of the most obvious behaviours, alarm is also one of the most difficult to define because of the wide range of responses that can be included within the term (Hölldobler \& Wilson, 1990). Generally alarm behaviour can be divided into aggressive and panic reactions (Wilson \& Regnier, 1971). Characteristic behaviours shown during aggressive alarm responses range from increased alertness to, in the most extreme cases, frenzied running and the biting or stinging of alien objects (Vander Meer \& Alonso, 1998).

Leaf-cutting ants (Hymenoptera: Formicidae: Attini: Atta and Acromyrmex) are dominant herbivores in the neotropics

Correspondence: W. O. H. Hughes, Zoological Institute, Department of Population Ecology, University of Copenhagen, Universitetsparken 15, 2100 Copenhagen, Denmark. Tel.: +45 353 21318; fax: +45353 21250; e-mail: WOHHughes@zi.ku.dk
(Hölldobler \& Wilson, 1990) and are one of the most destructive pests in these regions (Weber, 1972; Cherrett, 1986). They form large colonies with worker populations of up to 7 million individuals (Jonkman, 1980) that are highly polymorphic and polyethic. They exhibit an aggressive alarm response and release an alarm pheromone from the mandibular glands in their heads (Butenandt et al., 1959; Blum et al., 1968; Moser et al., 1968; Riley et al., 1974; Knapp, 1995; Pow, 1996; Hernández et al., 1999). The chemistry of this alarm pheromone has been the subject of a number of studies. Although early research identified only a small number of compounds in the alarm pheromones of Atta species (Blum et al., 1968; Moser et al., 1968; Riley et al., 1974), more recent work on A. sexdens rubropilosa (Schildknecht, 1976; Nascimento et al., 1993) and A. bisphaerica and A. capiguara (Hughes et al., 2001) has found the alarm pheromone to be a complex mixture of a large number of compounds. Very few studies have examined the behavioural activity of any of these compounds. Butenandt et al. (1959) claimed that citral was the compound responsible for the alarm reaction in Atta sexdens rubropilosa, whereas later studies have all concluded that 
4-methyl-3-heptanone is the most important releaser of alarm behaviour in Atta (Blum et al., 1968; Moser et al., 1968; Riley et al., 1974; Knapp, 1995; Pow, 1996). The only study to examine the precise behaviours involved was by Moser et al (1968). They injected 4-methyl-3-heptanone into a chamber containing Atta texana workers and found that at low levels ants would raise their heads and antennae. A higher concentration of $2.7 \times 10^{8}$ molecules $/ \mathrm{cm}^{3}$ caused workers to exhibit 'alarm', and run around frenetically with mandibles gaping open. At an intermediate concentration of $2.7 \times 10^{7}$ molecules $/ \mathrm{cm}^{3}$ of air, workers showed 'attraction' and moved towards one side of the chamber.

The application of single synthetic compounds is highly artificial when compared with the complex chemical cocktail that is released by ants in a natural situation. Minor components may act synergistically with 4-methyl-3-heptanone, and compounds may stimulate behaviours other than those being tested for in a bioassay. Therefore, it is important to establish the true level of response and behaviours involved in the natural alarm reaction. This can be done crudely by crushing the relevant gland to release its contents, or, where the mandibular glands produce the alarm pheromone, by crushing an ant head. This method has been used with many ant species (Hölldobler \& Wilson, 1990), including leafcutting ants (Blum et al., 1968; Moser et al., 1968; Hernández et al., 1999), and there is no difference in the volatiles contained in the mandibular glands and whole heads of leafcutting ants (Nascimento et al., 1993; Knapp, 1995).

As an ant may be exposed to more than one pheromone at a time in its natural environment, the signals in a natural alarm reaction can be multisource, as well as individual pheromones being multicomponent (Bradshaw \& Howse, 1984; Hölldobler \& Wilson, 1990). Leaf-cutting ants produce pheromones from a number of glands, and many of these are known to have attractive or arrestive properties (Howse \& Bradshaw, 1980; Bradshaw et al., 1986). There is even some evidence that secretions from the valves and Dufour's glands may produce full alarm responses (Hölldobler \& Wilson, 1986). Thus, the possibility of a multisource system also needs to be considered when examining the alarm reaction of leaf-cutting ants.

Synthetic versions of the main compounds in the mandibular secretions of Atta bisphaerica (Forel) and A. capiguara (Gonçalves) were tested using field colonies. Further experiments were then carried out using field colonies of A. capiguara. These examined some of the behaviours involved in the alarm reaction and compared the responses to the most effective of the synthetic compounds with those to natural alarm pheromone (crushed ant heads), and a multisource system (crushed ant heads with the body left attached). The responses of A. capiguara to crushed heads (without bodies) and crushed bodies (without heads) were also compared.

\section{Materials and Methods}

The experiments described here were carried out in Brazil during April 1996, October 1996 and October to December 1997. All of the ant trails used were from mature nests. The
A. bisphaerica nests were located near Viçosa, MG, Brazil, and the A. capiguara colonies were near Capinópolis, MG, Brazil. The experiments were carried out during the main period of foraging activity, and only trails with good activity (defined as a traffic of at least 25 ants/min) were selected.

The response of Atta bisphaerica to synthetic alarm compounds

Four of the most abundant compounds in the alarm pheromone of A. bisphaerica (4-methyl-2-hexanone, 4methyl-3-heptanone, 2-heptanone and 3-octanone) were tested to establish the response of the ants to them. These compounds differed little in volatility under the test conditions (Hughes, unpublished observations). In each replicate, $10 \mu \mathrm{L}$ of the test chemical was applied to a cigarette filter. This was then immediately placed $5 \mathrm{~cm}$ to one side of the entrance hole of the trail, in the centre of a $10-\mathrm{cm}$ diameter circle that had previously been cleared of vegetation (see Fig. 1). Blank filters with no chemical added were used as controls. Each of the five treatments was replicated five times using different trails.

The ant response was measured by counting the number of ants within the $10-\mathrm{cm}$ diameter circles centred on the sources. Near-instantaneous counts were made of the number of ants within the circles at $0.5,1,1.5,2.5,5,10,15$ and 20 min after application of the test filters. Counts were also made

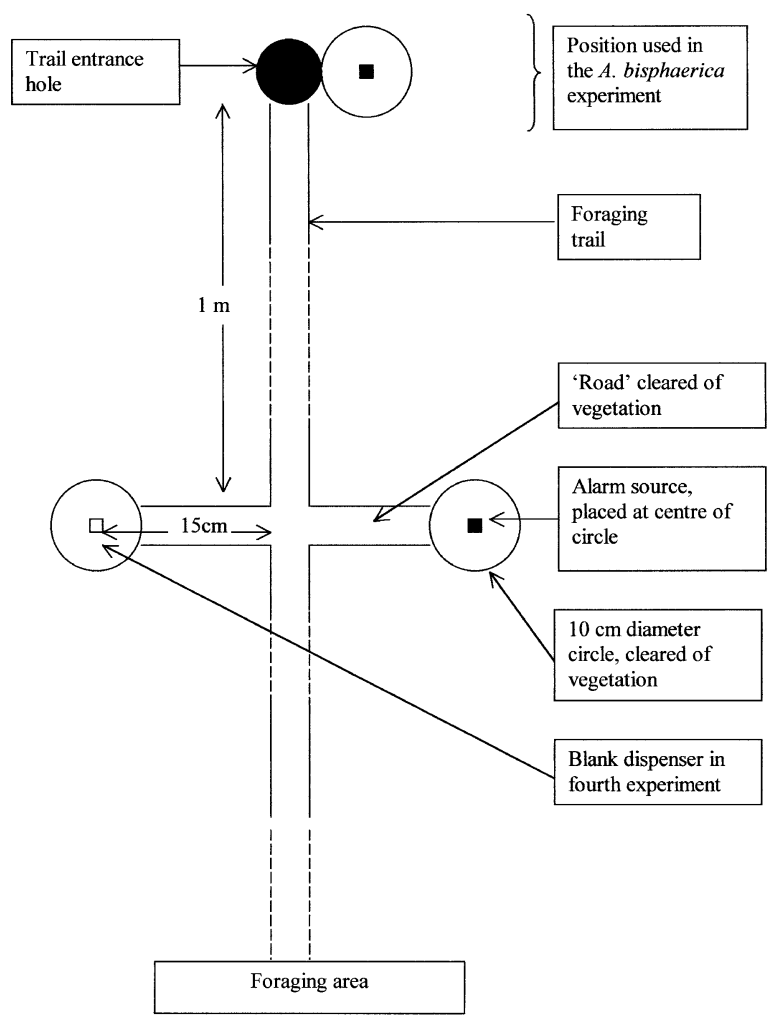

Fig. 1. Diagram of experimental set-up. 
immediately before application (time 0 ) in order to establish the number of ants normally in the areas.

The response of A. capiguara to synthetic alarm compounds

A similar experiment was carried out with A. capiguara in which 2-octanone and 4-methyl-3-hexanone were tested as well as the four compounds examined in the previous experiment. The sources were placed $5 \mathrm{~cm}$ to the side of the trails at $1 \mathrm{~m}$ from the entrance hole rather than beside the entrance hole as in the A. bisphaerica experiment. This was because small mounds of old grass and rubbish surrounded the A. capiguara trail entrances. $50 \mu \mathrm{L}$ of the chemicals were applied to rubber septa, which provide a slower release than do cigarette filters. Blank septa were used as controls. Counts of the number of ants within a $10-\mathrm{cm}$ diameter circle centred on the septum were made immediately before (time 0 ), and at 1, 2, 3, 4, 5, 15 and $30 \mathrm{~min}$ after application. Each compound was replicated 10 times using trails from different $A$. capiguara nests, to which they were randomly allocated.

\section{Comparison of the response to natural and synthetic alarm compounds}

Three different alarm sources were compared in this experiment, which was carried out with A. capiguara. The sources were: $50 \mu \mathrm{L}$ of 4-methyl-3-heptanone applied on rubber septa, crushed ant heads alone, and crushed ant heads with the bodies still attached. Blank rubber septa were used as controls. Each source was replicated 10 times using different trails. The alarm sources were placed $15 \mathrm{~cm}$ from the trail, at the centre of a $10-\mathrm{cm}$ diameter circle cleared of vegetation (see Fig. 1). The sources were connected to the trails by areas previously cleared of vegetation, termed 'roads', to allow the number of ants leaving the trail and travelling towards the source to be counted (see Fig. 1). Ant heads were obtained from foragers with a head width of between 2.5 and $3 \mathrm{~mm}$, which were removed from the experimental trail with forceps, and used immediately. Care was taken to avoid any contamination by abdominal secretions. One head or whole ant was then placed in the centre of the $10-\mathrm{cm}$ circle and the head in either case crushed using a clean metal rod.

Counts of the number of ants travelling along the trail during $30 \mathrm{~s}$ were made immediately before the application of the source (time 0 ) and at 2, 6 and 10 min afterwards. These counts were made at points on the trail either side of the junction with the road, and averaged to give a measure of trail activity. A similar 30-s count was made of the number of ants travelling past a point on the road $5 \mathrm{~cm}$ from the trail. This was also done at time 0 and at 2, 6 and $10 \mathrm{~min}$ after application. Finally, the number of ants within a $10-\mathrm{cm}$ diameter circle centred on the alarm source was recorded prior to the experiment (time 0 ) and at $0.5,1,1.5,2,6$ and $10 \mathrm{~min}$ after application of the source. The circles were observed for 30 -s periods, and the maximum number of ants inside the circle at any one point was recorded. The proportion of them showing one or more alarm behaviours was also estimated. Alarm behaviours were defined as a faster than normal locomotory rate, gaping mandibles, and snapping or biting. All of these behaviours were readily distinguishable from the normal behaviours shown by the ants.

The involvement of attraction and chemokinesis in the alarm response

Eleven trails from different nests of A. capiguara were used to confirm whether the reason for the increased number of ants diverting from the trail and travelling towards the alarm sources found in previous experiments was attraction or an increase in undirected movement. To test this, roads were created as before, but were cleared on both sides of the trails (see Fig. 1). $50 \mu \mathrm{L}$ of 4-methyl-3-heptanone on rubber septa were used as the test sources, and placed in the centre of $10 \mathrm{~cm}$ circles, $15 \mathrm{~cm}$ from the trail along one of the roads. Blank septa were placed simultaneously in the corresponding positions along the opposite roads. Immediately prior to the experiment, and at 2 and $5 \mathrm{~min}$ after application of the septa, 30-s traffic counts were made. This was done simultaneously for ants travelling along both the road leading to the alarm source (the 'test' road) and to the blank septum (the 'blank' road). If 4-methyl-3-heptanone stimulates an increase in undirected movement in the ants on the trail then it would be expected that a similar number would be counted travelling along both the test and blank roads. If, on the other hand, 4-methyl-3heptanone stimulates attraction then the number travelling along the test road towards the alarm source should be greater than that travelling along the blank road.

\section{Comparison of the ant response to heads and bodies}

An experiment was carried out to compare the responses of A. capiguara to crushed heads and crushed bodies (the thorax and abdomen). The body part was removed from a forager with a head width of between 2.5 and $3 \mathrm{~mm}$, which was taken from the experimental trail and used immediately. The body part was placed in the centre of a cleared circle of $10 \mathrm{~cm}$ diameter, the centre of which was $5 \mathrm{~cm}$ to the side of a trail, at a point $1 \mathrm{~m}$ from the entrance hole. The body part was then thoroughly crushed using clean forceps. Counts of the number of ants within the $10-\mathrm{cm}$ circle were made at 0.5 and $2 \mathrm{~min}$ after application of the body part. Each body part was replicated 13 times on different A. capiguara trails.

\section{Statistical analysis}

The data were analysed using one-way repeated measures analyses of variance (ANOVA). By examining the interaction between treatment and time, these tested the null hypothesis that the numbers of ants counted changed in the same way over the experimental period regardless of the treatment applied. Repeated measures designs are appropriate where measurements have been taken of the same replicates at several time 
points (Green, 1993; Paine, 1996). The count data were logtransformed (or $\log (x+1)$ where there were zero counts) prior to analysis in order that they met the assumptions of normality and homogeneity of variance. Where the data were proportions they were arcsine-transformed prior to analysis. In the case of the fourth experiment, the tests and blanks were not independent, and so repeated measures ANOVAs were carried out on them separately to test for each the null hypothesis that there was no effect of time on ant numbers. In this experiment, a matched-pairs $t$-test was then used to compare the number of ants on the test and blank roads at 5 min after application.

\section{Results}

The response of $\mathrm{A}$. bisphaerica to synthetic alarm compounds

There were significant differences between the treatments in the way the number of ants responding changed over time $\left(F_{32,160}=2.06, P=0.002\right)$. All of the chemicals tested caused an increase in the number of ants near the cigarette filters, while the numbers near the control filters did not change during the experiment (Fig. 2). The greatest effect was caused by 4-methyl-3-heptanone, which was the only compound to stimulate any alarm behaviour and produced a different timeresponse relationship from the other compounds. Ant numbers peaked slightly later and decreased much more slowly than in the other treatments. The most rapid response (Fig. 2) was to 4-methyl-3-heptanone.

The response of A. capiguara to synthetic alarm compounds

The change over time in the number of ants at the septa differed significantly between the treatments $\left(F_{42,441}=3.44\right.$,
$P<0.001)$. The only compound to cause a substantial increase was 4-methyl-3-heptanone (Fig. 3), and this was also the only compound to be associated with any alarm behaviour.

Comparison of the response to natural and synthetic alarm compounds

Prior to application of the treatments, very few ants were counted either on the roads or in the circles, and no alarmed ants were ever observed. This remained the case in the controls for the full experimental period, while application of the other sources caused increases in the three variables. Treatment was found to have a significant effect on the way in which the traffic of ants along the roads $\left(F_{9,105}=6.66, P<0.001\right)$, the number of ants in the circles $\left(F_{18,210}=5.30, P<0.001\right)$ and the percentage of these ants that were alarmed $\left(F_{12,156}=7.64\right.$, $P<0.001$ ) changed over the experimental period (Figs 4-6). The traffic along the trail did not change significantly during the experiment in any of the treatments (treatment-time interaction: $F_{9,105}=0.99, P=0.46$; main effect of time: $F_{3,105}=1.68, P=0.18$ ). From the road and traffic counts it can be estimated that only $1.2 \pm 0.5 \%$ of ants travelling along the trail diverted down the road prior to application of the treatments. Two minutes after application, this had increased to $49.3 \pm 18.5 \%$ in the whole ant treatment and $16.8 \pm 4.7 \%$ when the crushed head was applied alone.

Whole ants with crushed heads caused the most marked response, followed by the crushed heads alone, with these treatments producing similar time-response patterns for the three measures. The response to 4-methyl-3-heptanone initially involved the fewest ants, and resulted in the lowest level of alarm behaviour. It also differed from the other treatments in that the road traffic continued to increase until $6 \mathrm{~min}$ after application; in the other treatments the traffic decreased after

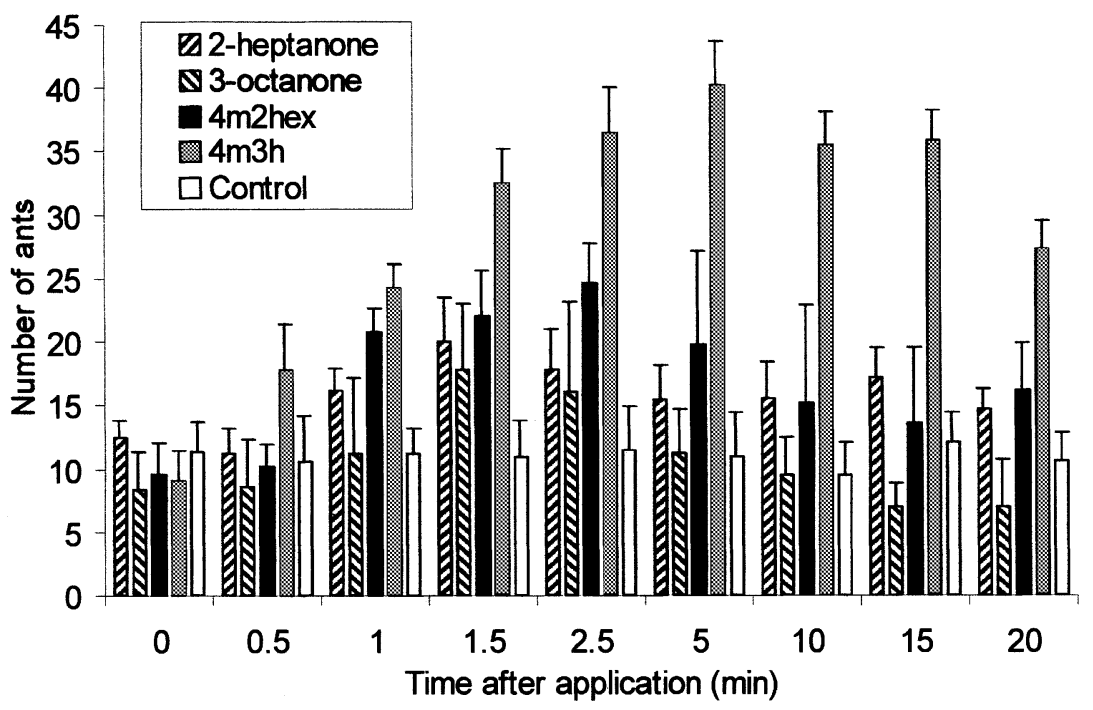

Fig. 2. Response of A. bisphaerica to four synthetic mandibular gland compounds. Mean ( \pm SE) numbers of ants within a $10-\mathrm{cm}$ circle centred on the source. Compounds were applied on cigarette filters at $10 \mu \mathrm{L}$ per filter ( $4 \mathrm{~m} 3 \mathrm{~h}=4$-methyl-3-heptanone, $4 \mathrm{~m} 2 \mathrm{hex}=4$-methyl-2-hexanone). 


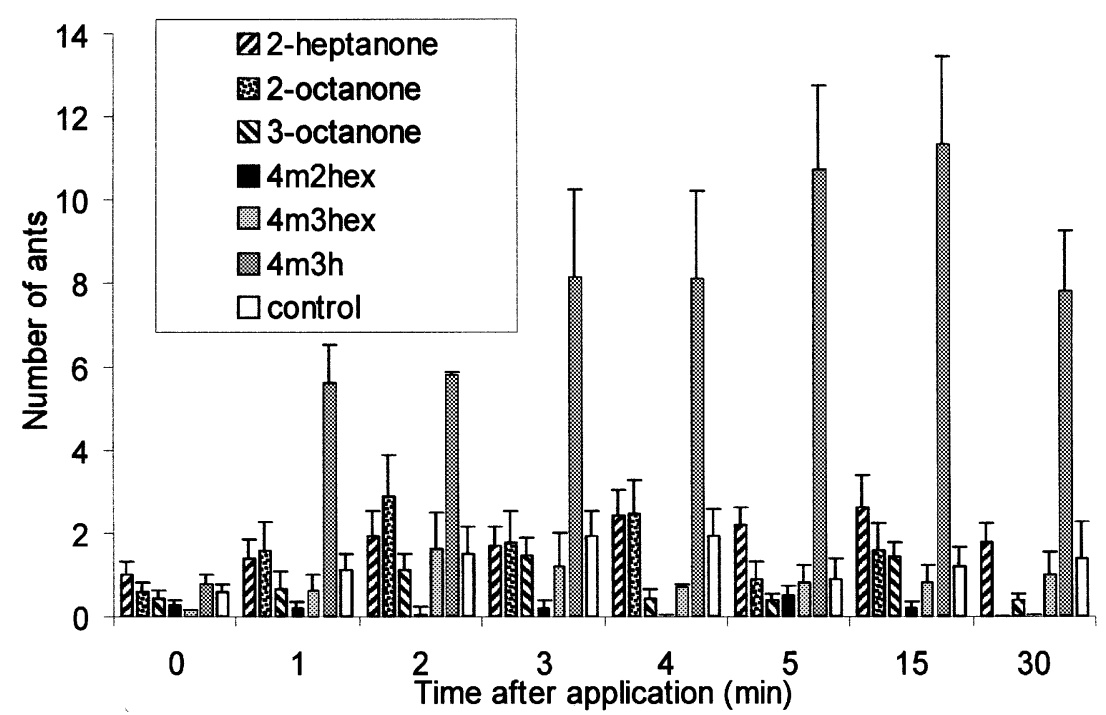

Fig. 3. Response of A. capiguara to six synthetic mandibular gland compounds. Mean $( \pm \mathrm{SE})$ numbers of ants within a $10-\mathrm{cm}$ circle centred on the source. Compounds were applied on rubber septa at $50 \mu \mathrm{L}$ per septum $(4 \mathrm{~m} 3 \mathrm{~h}=4$-methyl-3-heptanone, $4 \mathrm{~m} 2 \mathrm{hex}=4$-methyl-2-hexanone, $4 \mathrm{~m} 3$ hex $=4$-methyl-3-hexanone).

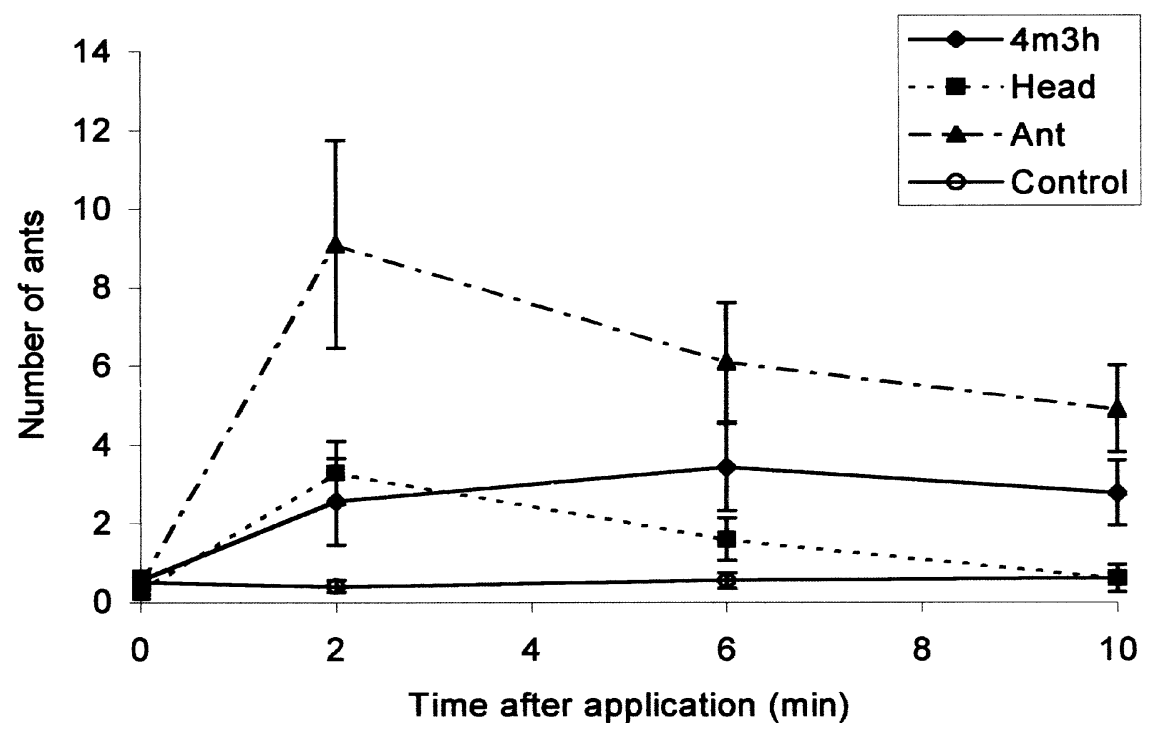

Fig. 4. Response of A. capiguara to alarm sources. Mean ( \pm SE) number of ants travelling along the road leading to the source. Alarm sources were: $50 \mu \mathrm{L}$ 4-methyl-3-heptanone $(4 \mathrm{~m} 3 \mathrm{~h})$ on a rubber septum; crushed ant head; whole ant with crushed head; and blank septum control.

2 min (Fig. 4). The ant responses to the two natural alarm source treatments (whole ant with crushed head, and crushed head alone) shared a number of features. The percentage of ants in the circle that were alarmed appeared to increase more rapidly than the other measures. This peaked after $1 \mathrm{~min}$, with an average of $85 \%$ of the ants within $5 \mathrm{~cm}$ of the whole ants showing alarm behaviours (Fig. 6). This variable also decreased the most rapidly, with very few ants showing alarm after $6 \mathrm{~min}$. The number of ants within the circle decreased at a slower rate than did the traffic of ants along the road. This was particularly obvious in the whole ant treatment, in which the number of ants in the circle actually continued to increase up to 6 min while the traffic along the road was decreasing after 2 min (Fig. 5).

The involvement of attraction and chemokinesis in the alarm response

Prior to the experiment, virtually no ants were observed travelling down either the test or blank roads. Following application of the septa, there was a significant increase in the 


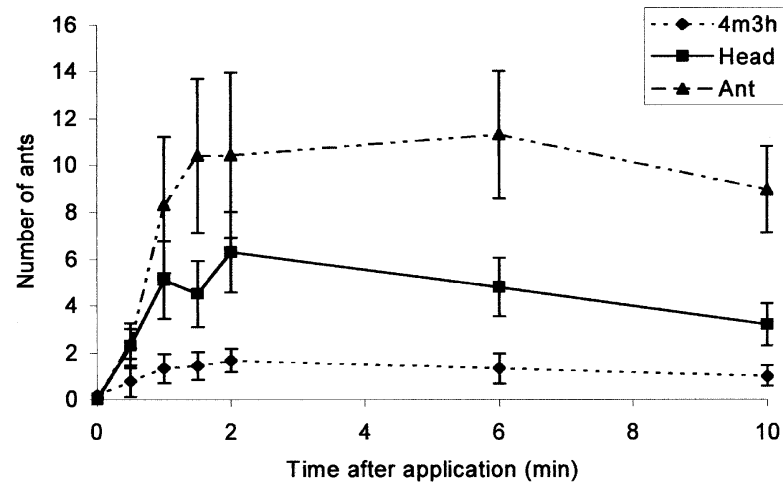

Fig. 5. Response of A. capiguara to alarm sources. Mean $( \pm \mathrm{SE})$ number of ants counted within a $10-\mathrm{cm}$ circle centred on the source. Alarm sources were: $50 \mu \mathrm{L}$ 4-methyl-3-heptanone $(4 \mathrm{~m} 3 \mathrm{~h})$ on a rubber septum; crushed ant head; and whole ant with crushed head. Control data excluded due to negligible numbers of ants recorded.

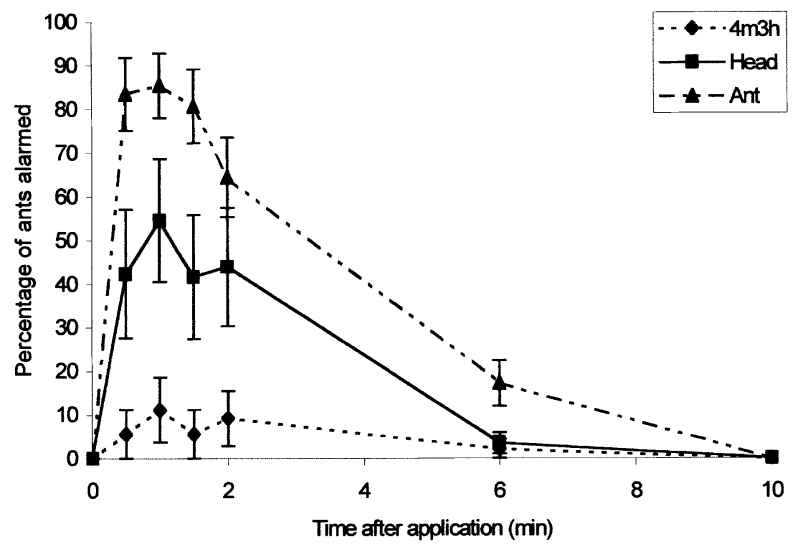

Fig. 6. Response of A. capiguara to alarm sources. Mean ( $\pm \mathrm{SE}$ ) percentage of ants within a $10-\mathrm{cm}$ circle centred on the source that exhibited alarm behaviour. Alarm sources were: $50 \mu \mathrm{L}$ 4-methyl-3heptanone $(4 \mathrm{~m} 3 \mathrm{~h})$ on a rubber septum; crushed ant head; and whole ant with crushed head. Ants near the controls never showed alarm.

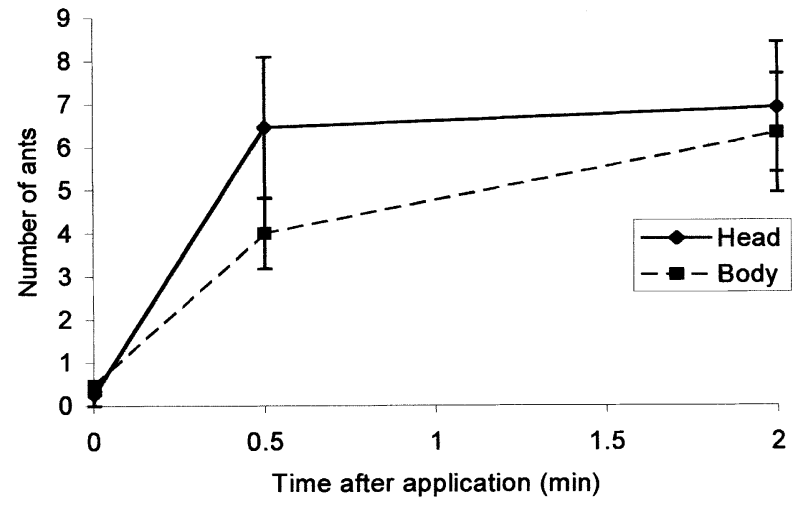

Fig. 7. Mean ( $\pm \mathrm{SE})$ number of A. capiguara workers counted within a $10-\mathrm{cm}$ circle centred on the source. Sources were either a crushed head or a crushed body (thorax + abdomen). number of ants travelling along the road leading to the test septa $\left(F_{2,20}=14.9, P<0.001\right)$. The number travelling towards the blank septa did not increase significantly $\left(F_{2,20}=1.85\right.$, $P=0.18$ ). At $5 \mathrm{~min}$ after application there were significantly more ants on the test roads than on the blank roads $(\mathrm{t}=4.69$, d.f. $=10, P=0.001)$.

\section{Comparison of the ant response to heads and bodies}

The numbers of ants counted in the test circles increased (Fig. 7) following application of crushed heads or crushed bodies (the thorax and abdomen), but at significantly different rates $\left(F_{4,72}=22.2, P<0.001\right)$. Numbers near the crushed heads increased faster than did numbers near the crushed bodies, but were virtually the same 2 min after application. Many of the ants that responded to the crushed heads showed characteristic alarm behaviours, such as gaping mandibles, snapping, or an increased rate of locomotion. In contrast, ants responding to the crushed bodies were not observed to show these behaviours.

\section{Discussion}

In both species, 4-methyl-3-heptanone was the compound that produced the greatest response from the ants. The numbers of ants near sources of this compound increased to a higher level than near any of the other compounds tested and it was the only compound to regularly stimulate alarm behaviour. This result is in accord with previous work on A. texana, A. sexdens, A. cephalotes and A. laevigata, in which 4-methyl-3-heptanone was also found to be the main instigator of alarm (Blum et al., 1968; Moser et al., 1968; Riley et al., 1974; Knapp, 1995; Pow, 1996). There are now both chemical and behavioural data for six of the 14 species of Atta, demonstrating 4-methyl-3heptanone to be the main compound in the alarm pheromone. In addition, this ketone has been found to be the most abundant compound in a further two species (A. colombica and A. robusta) (Blum et al., 1968). Such a lack of specificity has been predicted for alarm pheromones (Wilson, 1965; Blum, 1969; Law \& Regnier, 1971; Parry \& Morgan, 1979; Vander Meer \& Alonso, 1998). A similar situation seems to be the case in Pogonomyrmex, in which 4-methyl-3-heptanone is the major component of the alarm pheromone in seven species (McGurk et al., 1966; Vick et al., 1969). It has also been identified in the alarm pheromones of many other ant species and appears to be a relatively common alarm pheromone compound in ants generally (Hölldobler \& Wilson, 1990).

Unlike A. capiguara, A. bisphaerica did show some response to the other compounds tested, suggesting that they may also play a role in the alarm reaction of this species. This difference between the species though, is likely to have been simply due to the sources in the A. bisphaerica experiment being applied much closer to the trail entrance. Ant activity in this area was inherently far higher than at the position used in the A. capiguara experiment and ants are more likely to investigate stimuli close to their nest (Shorey, 1973). More ants 
would be expected to respond at this position, and it is possible that a weak response would have been stimulated by any chemical. The lesser responses exhibited by A. bisphaerica to 3-octanone, 2-heptanone and 4-methyl-2-hexanone should therefore be treated with caution.

There are essentially three behavioural mechanisms that could have been responsible for the increase in ant numbers near the sources during these experiments: 'attraction' (directed movement towards the source); an increase in undirected locomotion resulting in more ants encountering the source by chance (chemokinesis); and arrestment of ants actually encountering the source. In the third experiment the road traffic towards the source increased while the trail traffic did not, so either attraction or chemokinesis must have been occurring rather than solely arrestment. When the simultaneous traffic along test and blank roads was compared, only the traffic along the test roads increased. The movement was therefore directed and attraction was occurring. Attraction is involved in the alarm reactions of many ant species (Blum, 1969; Parry \& Morgan, 1979; Vander Meer \& Alonso, 1998), and Moser et al. (1968) and Knapp (1995) both concluded that 4-methyl-3-heptanone caused attraction in leaf-cutting ants. Sources of alarm pheromone also arrest ants commonly when they approach within a short distance of the source (Blum, 1969; Parry \& Morgan, 1979; Vander Meer \& Alonso, 1998). The fact that the number of ants near the crushed heads decreased more slowly than did the road traffic towards them, and the numbers near the whole ants actually continued to increase until $6 \mathrm{~min}$ after application, suggests that some degree of arrestment at the sources was also occurring.

Generally the whole ants produced a greater response than crushed heads alone, which in turn produced a greater response than 4-methyl-3-heptanone. Crushed ant bodies by themselves also caused an aggregation of ants near them, suggesting they are inherently attractive to ants. Leaf-cutting ant bodies (thorax and abdomen) contain at least five exocrine glands (Howse \& Bradshaw, 1980), several of which produce pheromones with attractive or arrestive properties (Moser, 1967; Riley et al., 1974; Robinson et al., 1974; Jaffé \& Howse, 1979; Hölldobler \& Wilson, 1986). Bodies alone did not result in the classic alarm behaviours, such as gaping mandibles and increased locomotory rate, that were caused by crushed heads. The responses caused by whole ants and crushed heads were qualitatively similar, but involved fewer ants when crushed heads were applied alone. These results support the established view that it is the mandibular glands of leaf-cutting ants that produce the main alarm pheromone compounds. It appears that compounds produced by glands in the thorax or abdomen are also attractive, and when applied with crushed heads, have an additive or synergistic effect on ant attraction.

Of the mandibular gland compounds tested with A. capiguara, 4-methyl-3-heptanone was the most active behaviourally, with none of the other compounds tested producing any significant response. However, when compared with natural alarm sources, 4-methyl-3-heptanone did not elicit the same response as the complete natural alarm pheromone produced by a crushed ant head. The road traffic increased for longer following the 4-methyl-3-heptanone treatment, which was probably due to the rubber septa giving a slower release of pheromone than the crushed heads. More interestingly, ant numbers within $5 \mathrm{~cm}$ of the crushed heads were more than three times higher than near the 4-methyl-3-heptanone sources, despite the ant traffic along the roads initially increasing to similar levels. The proportion of the ants that were alarmed was also far greater in the crushed head treatment. It appears, therefore, that although 4-methyl-3-heptanone had the same attractiveness as a crushed head, it did not have the same arrestive properties, nor did it stimulate the same level of the other alarm behaviours, such as gaping mandibles or biting. This may have been a result of the physical nature of the source (Maschwitz, 1966; Shorey, 1973; Vander Meer \& Alonso, 1998) or due to other compounds present in the crushed heads. Although none of the other five synthetic compounds tested produced any significant response from Atta capiguara, they may be synergistic in action, or may stimulate behaviours that would not be observed in the absence of the main component. Alternatively, one or more of the minor compounds not tested here may be involved in the alarm response. It appears that although 4-methyl-3-heptanone is the most active behaviourally of the main compounds in the alarm pheromone, other compounds in the mandibular glands also play a role.

\section{Acknowledgements}

We thank the Universidade Federal de Viçosa for providing support and facilities in Brazil. We are also grateful to John Bradshaw, Malcolm Cherrett and Jenny Knapp for commenting on earlier versions of this work. Financial support for the study was provided by Griffin LLC (Georgia, U.S.A.).

\section{References}

Blum, M.S. (1969) Alarm pheromones. Annual Review of Entomology, 14, 57-80.

Blum, M.S., Padovani, F. \& Amante, E. (1968) Alkanones and terpenes in the mandibular glands of Atta species (Hymenoptera: Formicidae). Comparative Biochemistry and Physiology, 26, 291-299.

Bradshaw, J.W.S. \& Howse, P.E. (1984) Sociochemicals of ants. Chemical Ecology of Insects (ed. by W. J. Bell and R. T. Cardé), pp. 429-473. Chapman \& Hall, London.

Bradshaw, J.W.S., Howse, P.E. \& Baker, R. (1986) A novel autostimulatory pheromone regulating transport of leaves in Atta cephalotes. Animal Behaviour, 34, 234-240.

Butenandt, A., Linzen, B. \& Lindauer, M. (1959) Uber einen Duftstoff aus der Mandibeldrüse der Blattshneiderameise Atta sexdens rubropilosa Forel. Archives d'Anatomie Microscopique et de Morphologie Expérimentale, 48, 13-19.

Cherrett, J.M. (1986) The economic importance and control of leafcutting ants. Economic Impact and Control of Social Insects (ed. by S. B. Vinson), pp. 165-192. Praeger, Westport, CT, U.S.A.

Green, R.H. (1993) Application of repeated measures designs in environmental impact and monitoring studies. Australian Journal of Ecology, 18, 81-98.

Hernández, J.V., Cabreera, A. \& Jaffe, K. (1999) Mandibular gland 
secretion in different castes of the leaf-cutter ant Atta laevigata. Journal of Chemical Ecology, 25, 2433-2444.

Hölldobler, B. \& Wilson, E.O. (1986) Nest area exploration and recognition in leafcutter ants (Atta cephalotes). Journal of Insect Physiology, 32, 143-150.

Hölldobler, B. \& Wilson, E.O. (1990) The Ants. Belknap Press of Harvard, Cambridge, Massachusetts.

Howse, P.E. \& Bradshaw, J.W.S. (1980) Chemical systematics of social insects with particular reference to ants and termites. Chemosystematics: Principles and Practice, Systematics Association Special, Vol. 16 (ed. by F. A. Bisby, J. G. Vaughan and C. A. Wright), pp. 71-90. Academic Press, London.

Hughes, W.O.H., Howse, P.E. \& Goulson, D. (2001) The mandibular gland chemistry of grass-cutting ants: species, caste and colony variation. Journal of Chemical Ecology, 27, 109-124.

Jaffé, K. \& Howse, P.E. (1979) The mass recruitment system of the leaf cutting ant, Atta cephalotes. Animal Behaviour, 27, 930-939.

Jonkman, J.C.M. (1980) Average vegetative requirement, colony size and estimated impact of Atta vollenweideri on cattle-raising in Paraguay. Zeitschrift für Angewandte Entomologie, 89, 135-143.

Knapp, J.J. (1995) Chemical aspects of communication and defence in leaf-cutting ants. $\mathrm{PhD}$ Thesis, University of Southampton, UK.

Law, J.H. \& Regnier, F.E. (1971) Pheromones. Annual Review of Biochemistry, 40, 533-548.

Maschwitz, U.W. (1966) Alarm substances and alarm behavior in social insects. Vitamins and Hormones, 24, 267-290.

McGurk, D.J., Frost, J., Eisenbraun, E.J., Vick, K., Drew, W.A. \& Young, J. (1966) Volatile compounds in ants: identification of 4-methyl-3-heptanone from Pogonomyrmex ants. Journal of Insect Physiology, 12, 1435-1441.

Moser, J.C. (1967) Trails of the leafcutters. Natural History, New York, 7, 33-35.

Moser, J.C., Brownlee, R.C. \& Silverstein, R. (1968) Alarm pheromones of the ant Atta texana. Journal of Insect Physiology, $14,529-535$.

Nascimento, R.R., Morgan, E.D., Billen, J., Schoeters, E., Della Lucia, T.M.C. \& Bento, J.M. (1993) Variation with caste of the mandibular gland secretion in the leaf-cutting ant Atta sexdens rubropilosa. Journal of Chemical Ecology, 19, 907-918.
Paine, M.D. (1996) Repeated measures designs. Environmental Toxicology and Chemistry, 15, 1439-1441.

Parry, K. \& Morgan, E.D. (1979) Pheromones of ants: a review. Physiological Entomology, 4, 161-189.

Pow, E.M. (1996) The responses of workers of the leaf-cutting ant Atta sexdens rubropilosa (Forel) to their alarm pheromone. $\mathrm{PhD}$ Thesis, University of Southampton, UK.

Riley, R.G., Silverstein, R.M. \& Moser, J.C. (1974) Isolation, identification, synthesis and biological activity of volatile compounds from the heads of Atta. Journal of Insect Physiology, 20, 1629-1637.

Robinson, S.W., Moser, J.C., Blum, M.S. \& Amante, E. (1974) Laboratory investigations of the trail-following responses of four species of leaf-cutting ants with notes on the specificity of a trail pheromone of Atta texana (Buckley). Insectes Sociaux, 21, 87-94.

Schildknecht, H. (1976) Chemical Ecology - a chapter of modern natural products chemistry. Angewandte Chemie (International Edition), 15, 214-222.

Shorey, H.H. (1973) Behavioral responses to insect pheromones. Annual Review of Entomology, 18, 349-380.

Vander Meer, R.K. \& Alonso, L.E. (1998) Pheromone directed behavior in ants. Pheromone Communication in Social Insects (ed. by R. K. Vander Meer, M. D. Breed, K. E. Espelie and M. L. Winston), pp. 159-192. Westview Press, Boulder, Colorado.

Vick, K.W., Drew, W.A., Eisenbraun, E.J. \& McGurk, D.J. (1969) Comparative effectiveness of aliphatic ketones in eliciting alarm behavior in Pogonomyrmex barbatus and P. comanche. Annals of the Entomological Society of America, 62, 380-381.

Weber, N.A. (1972) Gardening ants. The attines. Memoirs of the American Philosophical Society, 92, 1-146.

Wilson, E.O. (1965) Chemical communication in the social insects. Science, 149, 1064-1071.

Wilson, E.O. \& Regnier, F.E. (1971) The evolution of the alarmdefense system in the formicine ants. American Naturalist, 105, 279-289.

Accepted 3 March 2001 